\title{
Hybrid ARIMA-HyFIS Model for Forecasting Univariate Time Series
}

\author{
S.Alamelu Mangai \\ Research Scholar, \\ Dept. of Computer Applications, \\ School of Information \\ Technology, \\ Madurai Kamaraj University, \\ Madurai-625021 \\ India
}

\author{
Kasinathan Subramanian \\ Specialist, \\ System Development,
Verizon, \\ System Development,
Verizon, \\ Chennai, \\ India
}

(n)

\author{
K. Alagarsamy, Ph. D \\ Associate Professor, \\ Dept. of Computer Applications, \\ School of Information \\ Technology, \\ Madurai Kamaraj University, \\ Madurai-625021 \\ India
}

\author{
B. Ravi Sankar \\ Scientist, \\ MPAD/MDG \\ ISRO Satellite Centre \\ Bangalore-560017 \\ India
}

\begin{abstract}
In this paper, a novel hybrid model for fitting and forecasting a univariate time series is developed based on ARIMA and HyFIS models. The linear part is fitted using ARIMA model whereas the non-linear residual is fitted using HyFIS model. Clustering technique is used to determine the number of inputs and the membership functions of the HyFIS model. The hybrid model is applied to the wind speed data. The result is analyzed and compared on the basis of standalone ARIMA, standalone HyFIS and for the hybrid ARIMA-HyFIS model.
\end{abstract}

\section{General Terms}

ARIMA, ANFIS, DENFIS, HyFIS, Hybrid Algorithm

\section{Keywords}

ARIMA-HyFIS, ARIMA, HyFIS, Fuzzy Inference System, Clustering.

\section{INTRODUCTION}

Modeling and forecasting wind speed data is important to forecast weather. It is also significant to model the wind speed data to forecast the energy produced by wind mills. In this paper, a novel two stage hybrid ARIMA-HyFIS model for forecasting wind speed is developed. The wind speed data is taken using buoy (station 42059) by NDBC at the latitude 15.054 $\mathrm{N}$ and longitude 67.472 $\mathrm{W}$ for the whole of year 2013 [1]. The data are modeled first by ARIMA followed by HyFIS and then by hybrid ARIMA-HyFIS. The results are discussed in detail.

Throughout this paper the meaning of a quarter is 3 months starting from January not economic quarter which normally begins at April. The rest of the research is organized as follows. In section 2, literature review is presented. Section 3 describes the basic concepts of HyFIS model and data preparation using cluster analysis. In section 4 , the wind speed data is applied to different models and the results obtained are discussed. Section 5 concludes this paper.

\section{LITERATURE REVIEW}

Box and Jenkins [2] developed the autoregressive moving average to predict time series. There exists a vast literature for forecasting a univariate time series model based on neuro- fuzzy inference system. A fuzzy ARIMA model for forecasting foreign exchange market is presented in [3]. A hybrid ARIMA and neural network approach for forecasting time series is presented in [4]. "Al-Fuhaid et al." developed a neural network based short term load forecasting in Kuwait [5]. "Che et al." developed a hybrid model for forecasting short term electricity prices based on ARIMA and support vector regression [6]. Different hybrid forecasting approaches are evaluated in [7]. "Chengqun Yin et al." forecasted short term load based on hybrid neural network model [8].

Fuzzy rule based system based on learning from example was developed by Wang and Mendel [9]. Jang developed a neural network based fuzzy inference system which later on named as ANFIS [10] [11]. ANFIS stands for adaptive network based fuzzy inference system. ANFIS is a hybrid model in the sense it uses both neural network and fuzzy logic. Kim and Kasabov developed a hybrid model which later on denoted by HyFIS [12]. The difference between ANFIS and HyFIS is discussed in the next section. Kasabov and Song developed a dynamically evolving neural network model which later on denoted by DENFIS [13]. DENFIS stands for dynamically evolving network based fuzzy inference system. Later on evolutionary algorithms are used to tune the parameters of the hybrid neuro-fuzzy inference systems [14].

In [15], a hybrid model is presented to forecast the short-term electricity load in Indonesia based on ARIMA-ANFIS architecture. "Ren Ye et al." developed a hybrid ARIMADENFIS method for forecasting wind speed [16].

\section{OVERVIEW OF HYFIS MODEL AND DATA PREPARTION}

\subsection{Overview of HyFIS Model}

The architecture of HyFIS model is presented in this section. Fig. 1 describes the architecture of a HyFIS model in which three membership functions are used for the two inputs. In this model, nine rules are used. In this figure a square node denotes an adaptive node and circular node denotes a fixed node. The difference between the ANFIS and HyFIS models are given below. 
- The membership function can take any shape in ANFIS whereas in HyFIS the membership functions are only Gaussian. Since HyFIS uses Gaussian MF, only two parameters need to be optimized i.e. mean and variance of the membership function.

- $\quad$ The ANFIS uses Takagi Sugeno Kang model [17] (TSK) in the consequent part whereas HyFIS model uses a Mamdani model [18]

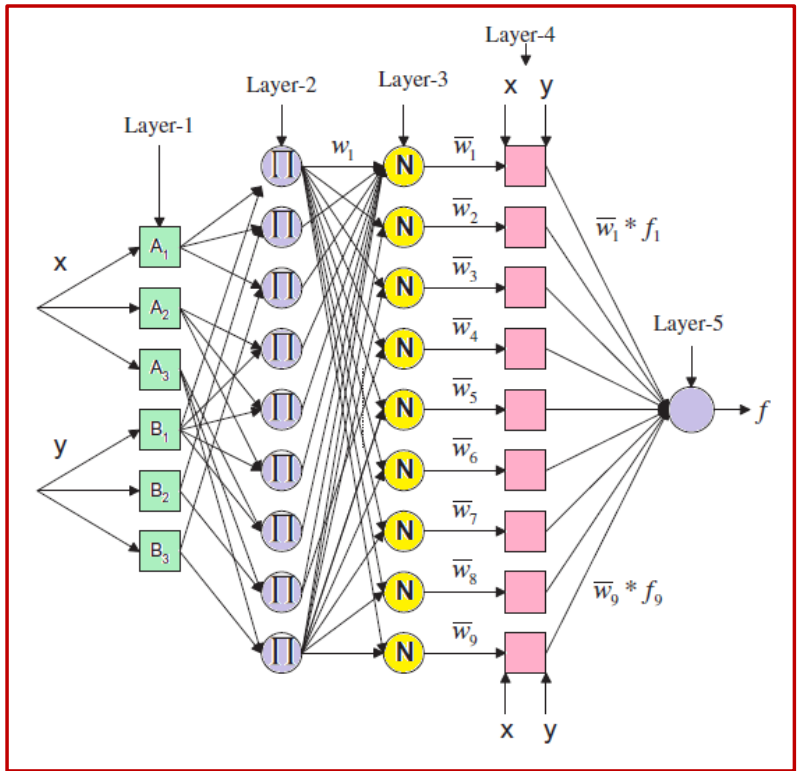

Fig 1: Two input nine rule HyFIS architecture

Layer 1 is the antecedent node in which inputs are applied. Layer 2 is the multiplication node and it simply multiplies the input signal and calculates the firing strength of each rule. Layer 3 is the rule node which calculates the relative firing strength of each rule. Layer 4 is the consequent node where consequent parameters are calculated and de-fuzzification takes place. Layer 5 is the output node which sums over all of the input and calculates the output. The learning of structure and parameters is a supervised learning method using gradient descent-based learning algorithms. The parameters of the square node are determined using supervised learning technique with help of training data. The training data consists of input and output parameters of the system to be identified.

\subsection{Data Preparation Using Clustering}

The wind speed data is taken for the whole of the year 2013 with a sampling time of 10 minutes. The analysis is carried out in the following way. The data as whole of a year is considered followed by four quarter data. For this purpose the whole of the year data is split into four quarters. In order to determine the number of inputs for the HyFIS model, the data is clustered and the number of clusters is used as number of inputs to the HyFIS model. The number of membership function in each case is set equal to the number of clusters available in the data set. The fitted ARIMA model $p, d, q$ are summarized in table 1. Figures 2-7 depict cluster obtained for different cases. ARIMA model is fitted using the $\mathrm{R}$ language [19].
Table 1. Order of ARIMA models fitted for each case

\begin{tabular}{|c|c|c|c|}
\hline Case & $\begin{array}{l}\text { order } \\
(p, d, q)\end{array}$ & $\theta$ & $\phi$ \\
\hline $\begin{array}{l}\text { Q1 } \\
\text { data }\end{array}$ & $(3,1,2)$ & $\begin{array}{lll}0.48 & 0.18 & 0.10\end{array}$ & $-0.93-0.015$ \\
\hline $\begin{array}{l}\text { Q2 } \\
\text { data }\end{array}$ & $(4,1,2)$ & $\begin{array}{llll}0.13 & 0.50 & 0.19 & 0.08\end{array}$ & $-0.33-0.58$ \\
\hline $\begin{array}{l}\text { Q3 } \\
\text { data }\end{array}$ & $(5,1,3)$ & $\begin{array}{lll}0.014 & -0.44 & 0.72 \\
0.34 & 0.12 & \\
\end{array}$ & $\begin{array}{ll}-0.51 & 0.48 \\
-0.97 & \\
\end{array}$ \\
\hline $\begin{array}{l}\text { Q4 } \\
\text { data }\end{array}$ & $(4,1,4)$ & $\begin{array}{llll}0.39 & 0.05 & 0.67 & 0.02\end{array}$ & $\begin{array}{lll}-0.15 & -0.3 & -0.69 \\
0.32 & & \\
\end{array}$ \\
\hline $\begin{array}{l}\text { Entire } \\
\text { year }\end{array}$ & $(6,1,3)$ & $\begin{array}{llll}-0.22 & 0.15 & 0.36 & 0.15 \\
0.05 & 0.01 & & \end{array}$ & $\begin{array}{ll}-0.28 & -0.27 \\
-0.33 & \end{array}$ \\
\hline
\end{tabular}

The order and the coefficients of the ARIMA model fitted for each of the five cases is tabulated in table 1 . The data and the residuals of the ARIMA model is clustered using three different clustering techniques namely $\mathrm{k}$-means clustering [20], fuzzy C-means clustering [21] [22] and subtractive clustering [23]. The results of the clustering are summarized in table 2.

\section{Clusters for the year 2013}

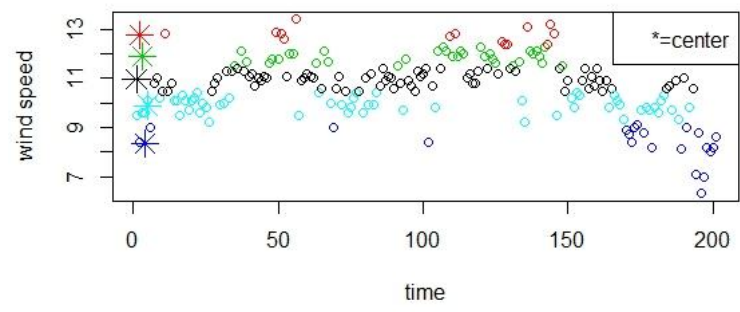

Fig 2: Five clusters for the entire data

Clusters for residuals 2013

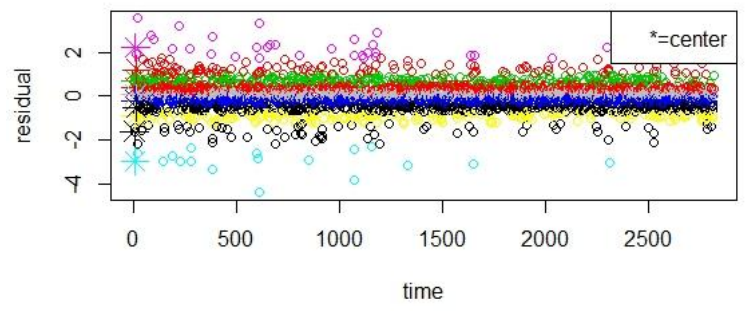

Fig 3: Ten clusters for the residual of year case

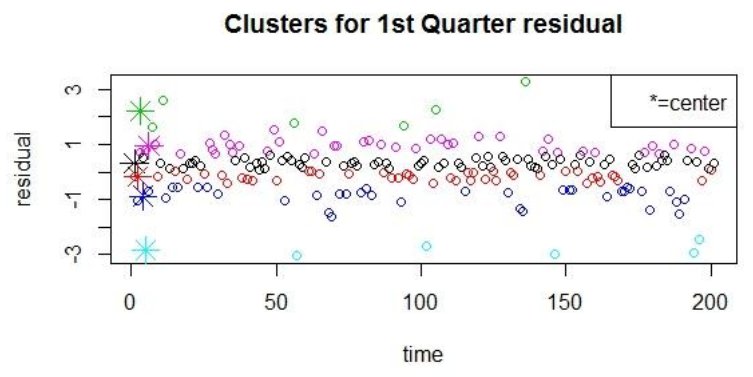

Fig4: Six clusters for the residual of Q1 


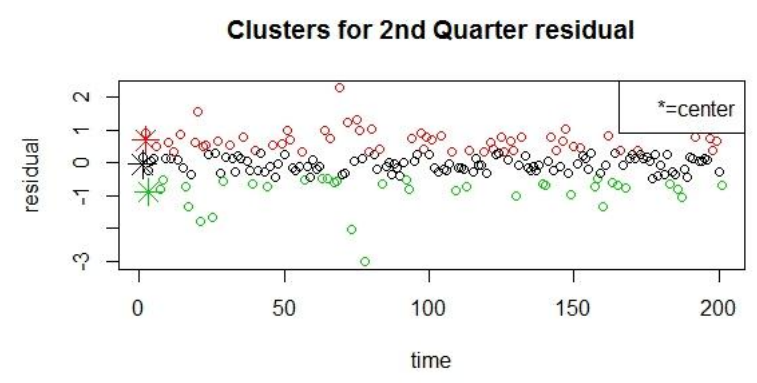

Fig 5: Three clusters for the residual of Q2

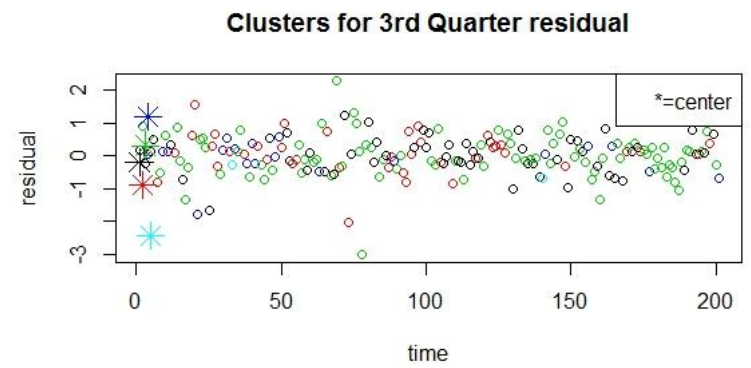

Fig 6: Five clusters for the residual of Q3

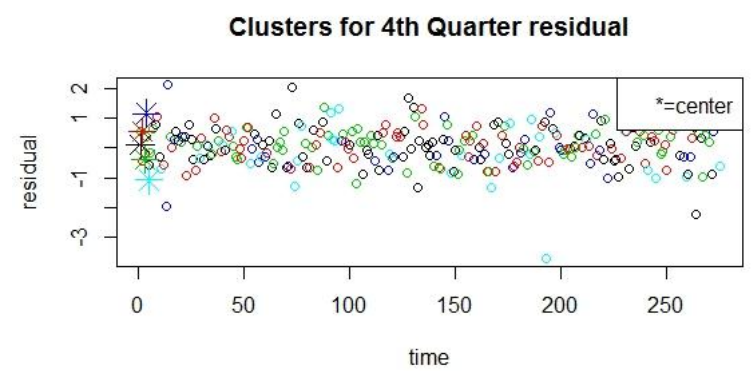

Fig 7: Five clusters for the residual of Q4

Table 2. Comparison of different clustering techniques

\begin{tabular}{|l|l|l|l|l|l|l|}
\hline case & \multicolumn{2}{|l|}{$\begin{array}{l}\text { K-means } \\
\text { Clustering }\end{array}$} & \multicolumn{2}{l|}{$\begin{array}{l}\text { Fuzzy C-mean } \\
\text { Clustering }\end{array}$} & \multicolumn{2}{l|}{$\begin{array}{l}\text { Subtractive } \\
\text { Clustering }\end{array}$} \\
\cline { 2 - 7 } & MAE & RMSE & MAE & RMSE & MAE & RMSE \\
\hline Q1 data & 0.612 & 0.521 & 0.692 & 0.598 & 0.512 & 0.421 \\
\hline $\begin{array}{l}\text { Q1 } \\
\text { residual }\end{array}$ & 0.721 & 0.597 & 0.721 & 0.674 & 0.631 & 0.543 \\
\hline Q2 data & 0.591 & 0.497 & 0.667 & 0.574 & 0.491 & 0.401 \\
\hline $\begin{array}{l}\text { Q2 } \\
\text { residual }\end{array}$ & 0.647 & 0.589 & 0.712 & 0.657 & 0.557 & 0.519 \\
\hline Q3 data & 0.609 & 0.514 & 0.698 & 0.672 & 0.527 & 0.453 \\
\hline $\begin{array}{l}\text { Q3 } \\
\text { residual }\end{array}$ & 0.649 & 0.573 & 0.687 & 0.659 & 0.543 & 0.475 \\
\hline Q4 data & 0.631 & 0.498 & 0.736 & 0.631 & 0.549 & 0.487 \\
\hline $\begin{array}{l}\text { Q4 } \\
\text { residual }\end{array}$ & 0.641 & 0.574 & 0.715 & 0.659 & 0.558 & 0.438 \\
\hline $\begin{array}{l}\text { Entire } \\
\text { year }\end{array}$ & 0.713 & 0.690 & 0.759 & 0.712 & 0.631 & 0.573 \\
\hline $\begin{array}{l}\text { Entire } \\
\text { year } \\
\text { residual }\end{array}$ & 0.871 & 0.801 & 0.931 & 0.879 & 0.819 & 0.712 \\
\hline
\end{tabular}

From table 2, it is clear that $\mathrm{K}$-means clustering produces a moderate MAE and lower RMSE than other techniques. The other techniques produce a result that is comparable with the $\mathrm{K}$-means clustering. The computing time for K-means clustering is lesser than other techniques and hence it is chosen for this analysis. Based on K-means clustering the number of inputs and the number of membership functions are determined and they are summarized in table 3 . It is to be noted that the number of clusters is equal to the number of inputs and also equal to the number of membership functions for each case.

Table 3. Number of clusters and inputs for each case

\begin{tabular}{|l|l|l|l|}
\hline Case & $\begin{array}{l}\text { Number of } \\
\text { clusters }\end{array}$ & $\begin{array}{l}\text { Number of } \\
\text { inputs }\end{array}$ & $\begin{array}{l}\text { Number of } \\
\text { member-ship } \\
\text { functions for } \\
\text { each variable }\end{array}$ \\
\hline Q1 data & 3 & 3 & 3 \\
\hline Q1 residuals & 6 & 6 & 6 \\
\hline Q2 data & 4 & 4 & 4 \\
\hline Q2 residuals & 3 & 3 & 3 \\
\hline Q3 data & 5 & 5 & 5 \\
\hline Q3 residuals & 5 & 5 & 5 \\
\hline Q4 data & 4 & 4 & 4 \\
\hline Q4 residuals & 5 & 5 & 5 \\
\hline Entire year & 5 & 5 & 5 \\
\hline $\begin{array}{l}\text { Entire year } \\
\text { residuals }\end{array}$ & 10 & 10 & 10 \\
\hline
\end{tabular}

The definition of error measures used to evaluate this model is given below.

$$
\begin{aligned}
& \text { MAE }=E[|\hat{x}(t)-x(t)|] \\
& \text { MAPE }=E\left[\left|\frac{\hat{x}(t)-x(t)}{x(t)}\right|\right] \times 100 \% \\
& \text { RMSE }=\sqrt{E\left[(\hat{x}(t)-x(t))^{2}\right]}
\end{aligned}
$$




\section{EXPERIMENTAL RESULTS}

Five cases are studied in this work as shown in table 1. In each case an ARIMA model, a HyFIS model and a hybrid ARIMA-HyFIS model is applied. The testing results are shown in the following tables.

Table 4. Error measures for 3 hour ahead forecasting

\begin{tabular}{|l|l|l|l|l|}
\hline Case & & ARIMA & HyFIS & $\begin{array}{l}\text { ARIMA- } \\
\text { HyFIS }\end{array}$ \\
\hline \multirow{4}{*}{ Q1 } & MAE & 0.11 & 0.13 & 0.11 \\
\cline { 2 - 5 } & MAPE & 11.33 & 13.75 & 11.54 \\
\cline { 2 - 5 } & RMSE & 0.13 & 0.15 & 0.13 \\
\hline \multirow{4}{*}{ Q3 } & MAE & 0.09 & 0.10 & 0.08 \\
\cline { 2 - 5 } & MAPE & 12.33 & 15.73 & 12.05 \\
\cline { 2 - 5 } & RMSE & 0.12 & 0.14 & 0.10 \\
\cline { 2 - 5 } & MAE & 0.09 & 0.12 & 0.11 \\
\cline { 2 - 5 } & MAPE & 11.73 & 14.75 & 11.98 \\
\cline { 2 - 5 } & RMSE & 0.11 & 0.16 & 0.13 \\
\hline & MAE & 0.09 & 0.14 & 0.09 \\
\cline { 2 - 5 } & MAPE & 12.09 & 15.19 & 11.87 \\
\cline { 2 - 5 } & RMSE & 0.12 & 0.16 & 0.12 \\
\hline Entire year & MAE & 0.12 & 0.15 & 0.11 \\
\cline { 2 - 5 } & MAPE & 12.87 & 16.89 & 11.06 \\
\cline { 2 - 5 } & RMSE & 0.14 & 0.17 & 0.12 \\
\hline
\end{tabular}

In Table 4, error measures of 3 hour ahead forecasting results are summarized. Table 5 summarizes the error measures of 6 hour ahead forecasting. Table 6 summarizes the error measures of 9 hour ahead forecasting. Figure 8 to figure 12 depict the ARIMA, HyFIS and ARIMA-HyFIS model used for 3 hours ahead forecasting for different cases (In figures only 100 minute ahead forecasting is shown for the sake of clarity of figures). Figure 13 shows MAPE versus period of forecasting for $3^{\text {rd }}$ quarter in which ARIMA model has outperformed ARIMA-HyFIS model.
Table 5. Error measures for 6 hour ahead forecasting

\begin{tabular}{|l|l|l|l|l|}
\hline Case & & ARIMA & HyFIS & $\begin{array}{l}\text { ARIMA- } \\
\text { HyFIS }\end{array}$ \\
\hline Q1 & MAE & 0.15 & 0.17 & 0.14 \\
\cline { 2 - 5 } & MAPE & 18.23 & 21.85 & 16.78 \\
\cline { 2 - 5 } & RMSE & 0.17 & 0.19 & 0.16 \\
\hline Q2 & MAE & 0.15 & 0.14 & 0.11 \\
\cline { 2 - 5 } & MAPE & 19.45 & 23.83 & 18.07 \\
\cline { 2 - 5 } & RMSE & 0.18 & 0.17 & 0.15 \\
\hline \multirow{4}{*}{ Q3 } & MAE & 0.13 & 0.18 & 0.14 \\
\cline { 2 - 5 } & MAPE & 17.83 & 21.75 & 18.94 \\
\cline { 2 - 5 } & RMSE & 0.16 & 0.21 & 0.17 \\
\hline \multirow{4}{*}{ Entire year } & MAE & 0.14 & 0.19 & 0.14 \\
\cline { 2 - 5 } & MAPE & 19.08 & 23.09 & 17.98 \\
\cline { 2 - 5 } & RMSE & 0.19 & 0.23 & 0.17 \\
\cline { 2 - 5 } & MAE & 0.18 & 0.21 & 0.15 \\
\cline { 2 - 5 } & MAPE & 18.77 & 23.79 & 17.76 \\
\cline { 2 - 5 } & RMSE & 0.21 & 0.25 & 0.19 \\
\hline
\end{tabular}

Table 6. Error measures for 9 hour ahead forecasting

\begin{tabular}{|l|l|l|l|l|}
\hline Case & & ARIMA & HyFIS & $\begin{array}{l}\text { ARIMA- } \\
\text { HyFIS }\end{array}$ \\
\hline Q1 & MAE & 0.17 & 0.19 & 0.16 \\
\cline { 2 - 5 } & MAPE & 27.54 & 30.65 & 25.18 \\
\cline { 2 - 5 } & RMSE & 0.21 & 0.23 & 0.19 \\
\hline Q2 & MAE & 0.16 & 0.18 & 0.15 \\
\cline { 2 - 5 } & MAPE & 28.75 & 31.87 & 26.17 \\
\cline { 2 - 5 } & RMSE & 0.20 & 0.22 & 0.18 \\
\hline \multirow{4}{*}{ Q3 } & MAE & 0.14 & 0.21 & 0.16 \\
\cline { 2 - 5 } & MAPE & 25.18 & 29.86 & 26.98 \\
\cline { 2 - 5 } & RMSE & 0.17 & 0.25 & 0.19 \\
\hline \multirow{4}{*}{ Entire year } & MAE & 0.17 & 0.21 & 0.13 \\
\cline { 2 - 5 } & MAPE & 26.78 & 31.07 & 24.87 \\
\cline { 2 - 5 } & RMSE & 0.22 & 0.26 & 0.18 \\
\hline & MAE & 0.23 & 0.25 & 0.18 \\
\cline { 2 - 5 } & MAPE & 28.77 & 32.79 & 25.16 \\
\cline { 2 - 5 } & RMSE & 0.28 & 0.31 & 0.21 \\
\hline
\end{tabular}




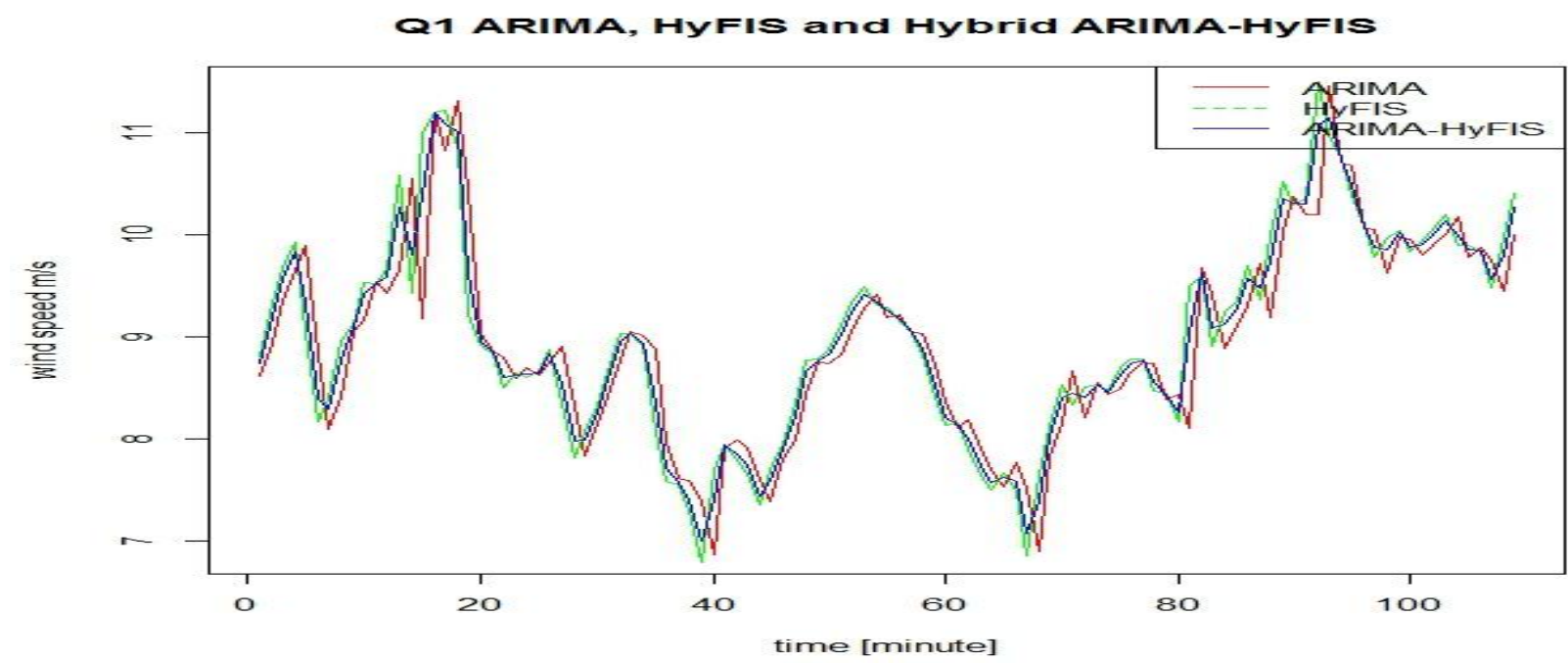

Fig 8: ARIMA-HyFIS model for three hours ahead forecasting for first quarter of 2013

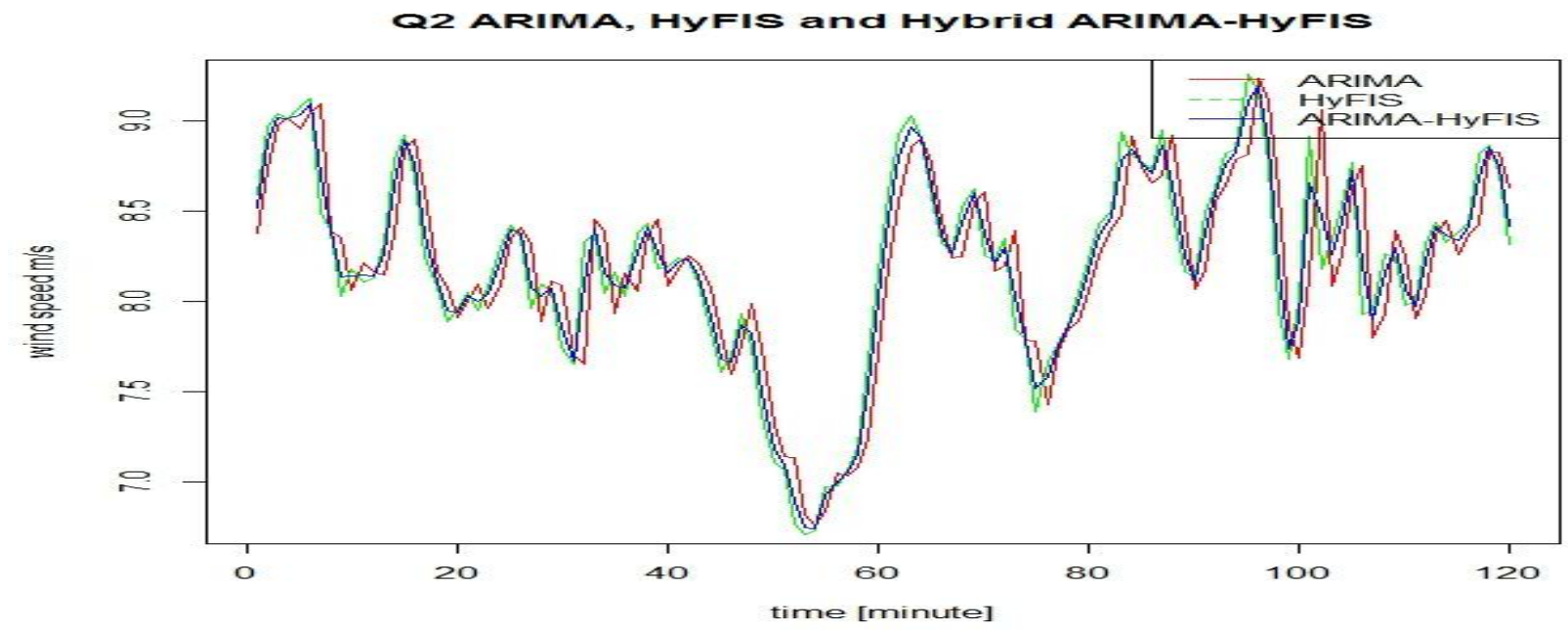

Fig 9: ARIMA-HyFIS model for three hours ahead forecasting for second quarter of 2013

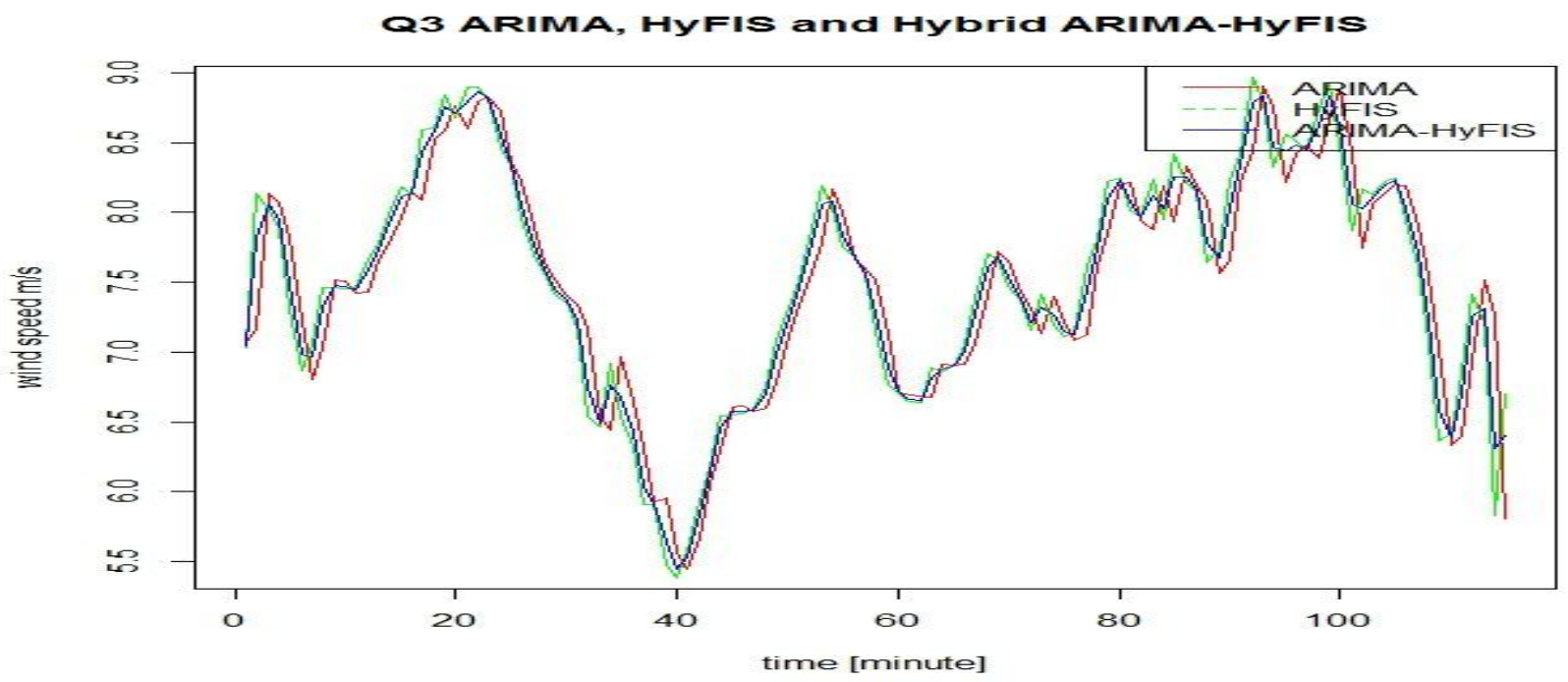

Fig 10: ARIMA-HyFIS model for three hours ahead forecasting for third quarter of 2013 


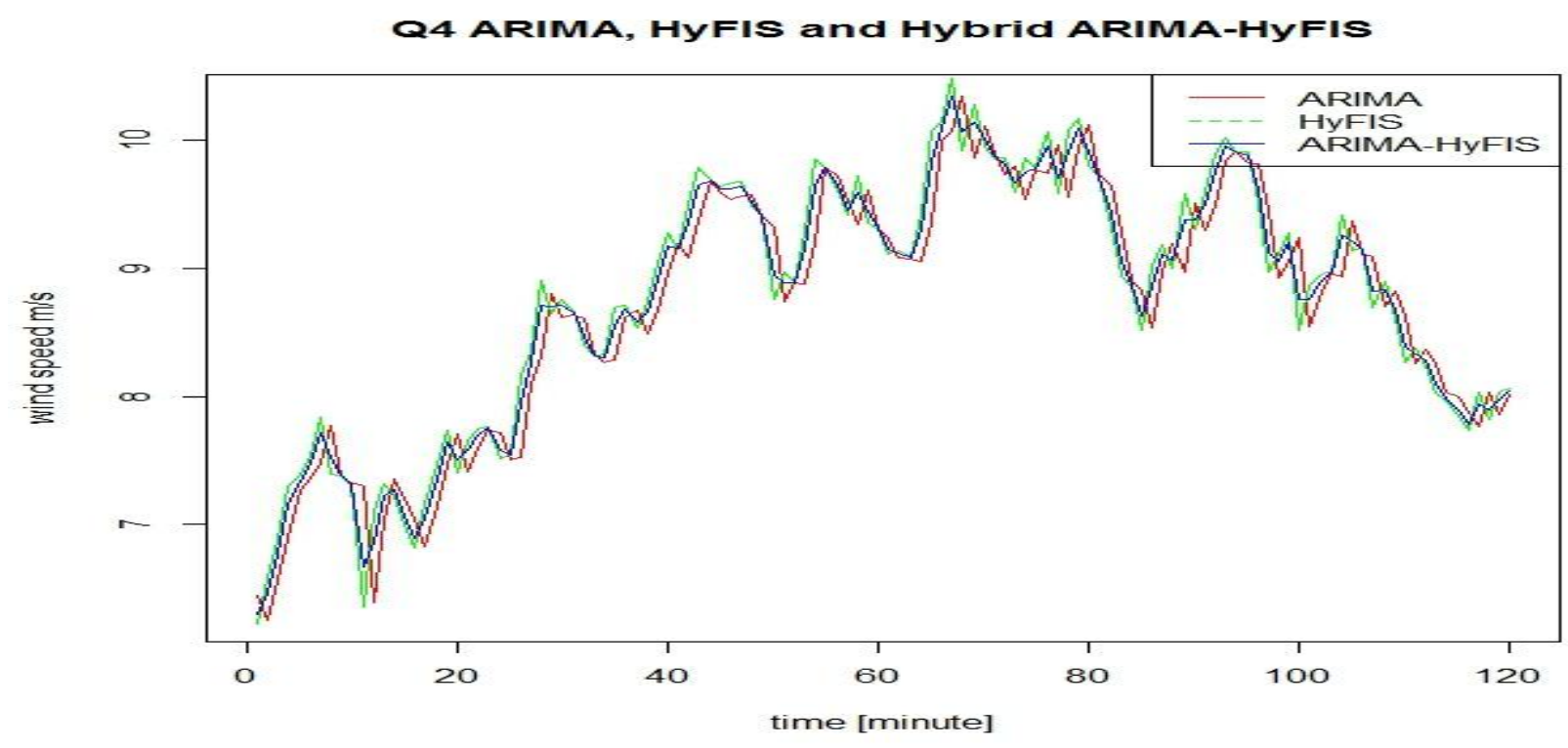

Fig 11: ARIMA-HyFIS model for three hours ahead forecasting for fourth quarter of 2013

ARIMA, HYFIS And HYbrid ARIMA-HYFIS for year 2013

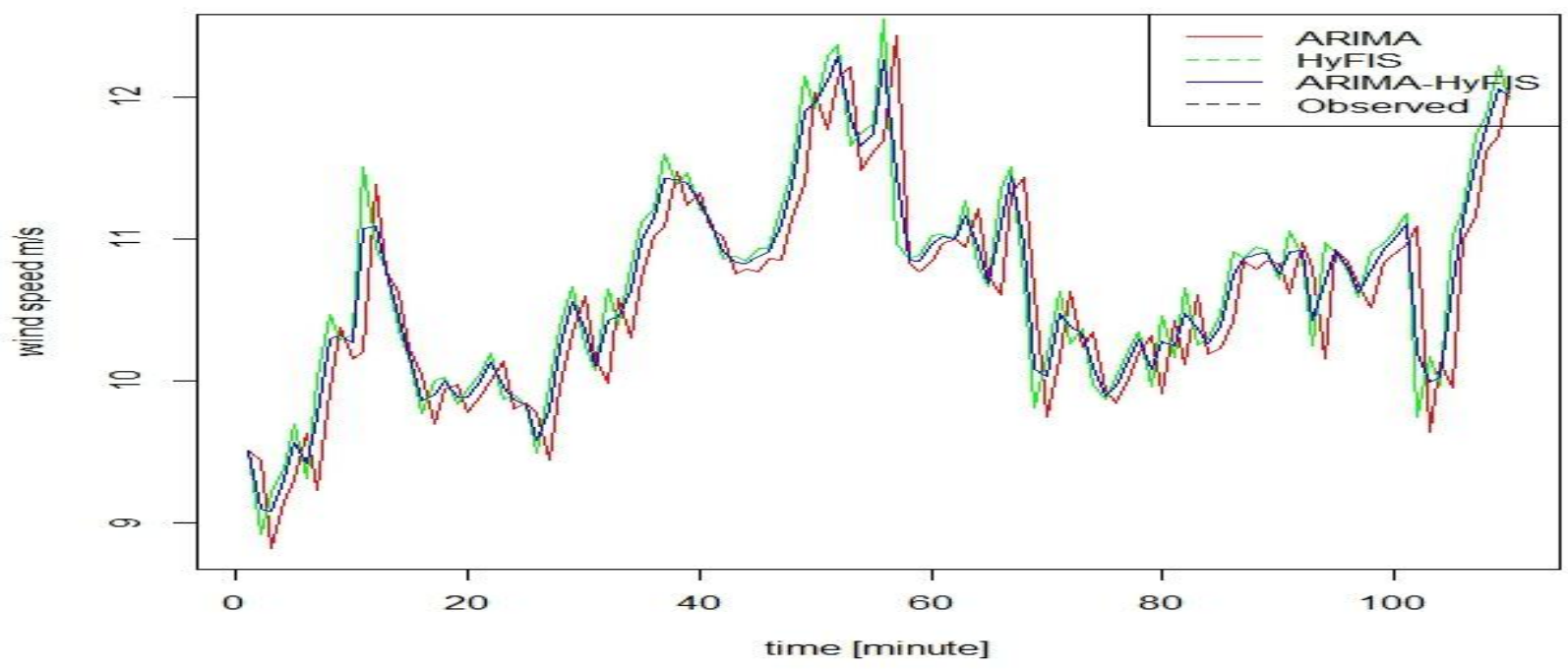

Fig 12: ARIMA-HyFIS model for three hours ahead forecasting for the entire year of 2013

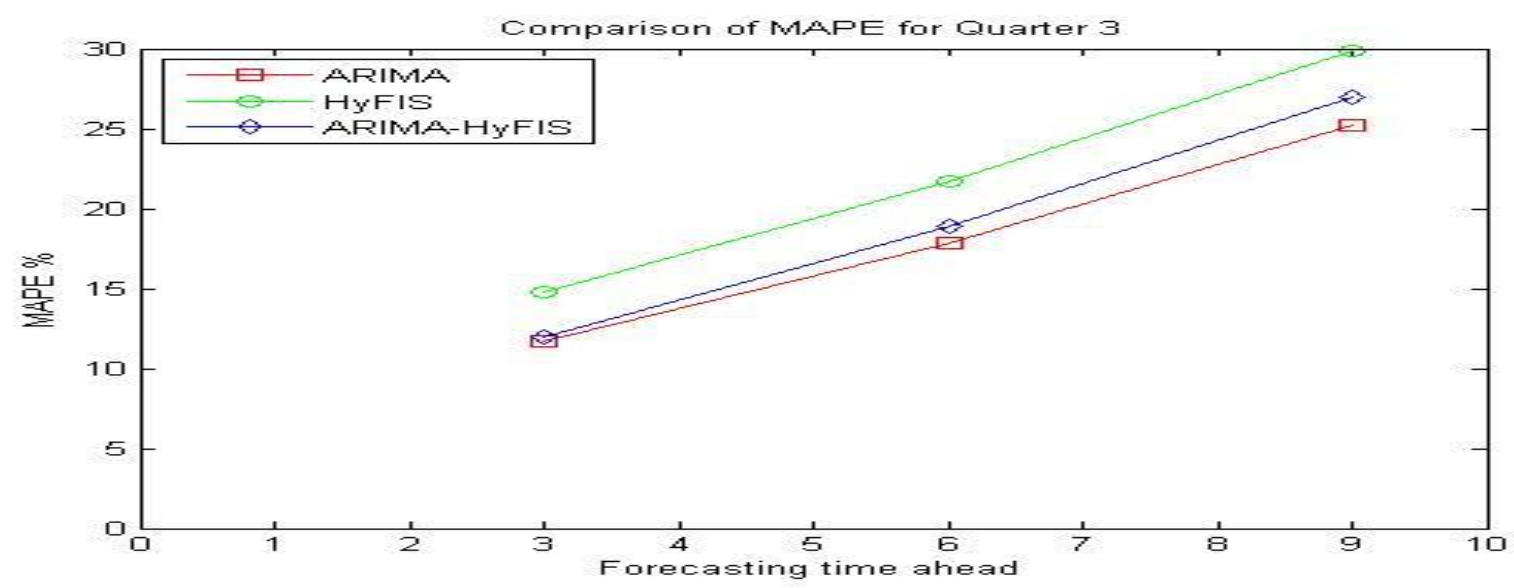

Fig 13: MAPE for third quarter 


\section{CONCLUSION}

This paper proposed a new hybrid ARIMA-HyFIS model for forecasting time series data. This model uses clustering technique to determine the number of inputs that are applied to the HyFIS model. The proposed model has been evaluated with NDBC wind speed data. The results are tabulated as well as pictorially represented. The proposed ARIMA-HyFIS model has outperformed the conventional ARIMA and HyFIS model in most of the cases. But in Q3, the ARIMA model has outperformed the hybrid ARIMA-HyFIS model. It is planned to tune the membership function's parameters using evolutionary algorithms.

\section{REFERENCES}

[1] (2013) National data buoy center historical data, [Online]. http://www.ndbc.noaa.gov/historical_data.html

[2] Box G.E.P, Jenkins G.M and Reinsel G.C, 1994, "Time Series Analysis, Forecasting and Control”, Prentice Hall.

[3] Fang-Mei Tseng, Gwo-Hshiung Tzeng, Hsiao-Cheng $\mathrm{Yu}$ and Benjamin J.C. Yuan, "Fuzzy ARIMA model for forecasting the foreign exchange market," Elsevier,Fuzzy Sets and Systems 118 (2001), pp.9-19.

[4] G. Peter Zhang, "Time series forecasting using a hybrid ARIMA and neural network model", Elsevier, Neurocomputing 50 (2003) 159 - 175.

[5] A.S. Al-Fuhaid, M.A. El-Sayed and M.S. Mahmoud, "Neuro-Short-Term Load Forecast of the Power System in Kuwait", Appl. Math. Modeling, vol 21, pp. 215-219, 1997.

[6] J. Che and J.Wang, "Short-term electricity prices on support vector regression and auto-regressive integrated moving average modeling", Energy Conversion and Management, vol. 51,pp.1911-1917, 2010

[7] J. Shi, J. Guo and S. Zheng, 'Evaluation of hybrid forecasting approaches for wind speed and power generation time series", Renewable and Sustainable Energy Reviews, vol. 16, pp. 3417-3480, 2012

[8] Chengqun Yin, Lifeng Kang and Wei Sun, "Hybrid Neural Network Model for Short-Term Load Forecasting", Third International Conference on Natural Computation (ICNC 2007), IEEE Computer Society.

[9] L.X. Wang and J. M. Mendel, "Generating fuzzy rule by learning from examples", IEEE Trans.Syst., Man, and Cybern.,vol. 22, no. 6, pp. 1414 - 1427 (1992).

[10] J.S.R.Jang, "ANFIS: adaptive-network-based fuzzy inference system", IEEE Transactions on Systems, Man, and Cybernetics, vol. 23, no. 3, pp. 665 - 685 (1993).

[11] J. S. R. Jang, C. T. Sun, and E. Mizutani., "Neuro-fuzzy and soft computing: a computational approach to learning and machine intelligence", Prentice-Hall Inc., (1997).
[12] J. Kim and N. Kasabov, "HyFIS: Adaptive neuro-fuzzy inference systems and their application to nonlinear dynamical systems", Neural Networks, vol. 12, no. 9, pp. 1301 - 1319(1999).

[13] N.K. Kasabov and Q. Song, "DENFIS: Dynamic evolving neural-fuzzy inference system and its Application for time-series prediction", IEEE Transactions on Fuzzy Systems, vol. 10, no. 2, pp. 144 154 (2002).

[14] Rafael Alcalá, Jesús Alcalá-Fdez and Francisco Herrera, "A Proposal for the Genetic Lateral Tuning of Linguistic Fuzzy Systems and Its Interaction With Rule Selection", IEEE Transaction on Fuzzy Systems, vol 15, no 4, pp. 616-635 (2007)

[15] Suhartono, Indah Puspitasari, M. Sjahid Akbar and Muhammad Hisyam Lee, "Two-level Seasonal Model Based on Hybrid ARIMA-ANFIS for Forecasting ShortTerm Electricity Load In Indonesia", International Conference on Statistics in Science, Business and Engineering (ICSSBE), IEEE, pp.1-5(2012)

[16] Ren Ye, P.N. Suganthan, Narasimalu Srikanth and Soham Sarkar, "A Hybrid ARIMA-DENFIS Method for Wind Speed Forecasting", IEEE International Conference on Fuzzy Systems (FUZZ),pp.1-6, 2013.

[17] T. Takagi and M. Sugeno, "Fuzzy identification of systems and its applications to modelling and control" ,IEEE transactions on systems, man, and cybernetics , vol. 15,no. 1, pp. 116-132, 1985

[18] E.H. Mamdani, "Application of fuzzy algorithms for control of simple dynamic plant", Proc. Inst. Elect. Eng. vol.121, no. 12, pp. $1585-1588$

[19] R Core Team, $R$ : A Language and Environment for Statistical Computing, R Foundation for Statistical Computing, Vienna, Austria, 2012, ISBN 3-900051-070 . Available at the URL : http://www.R-project.org

[20] MacQueen, J. B. (1967). "Some Methods for classification and Analysis of Multivariate Observations". Proceedings of 5th Berkeley Symposium on Mathematical Statistics and Probability 1. University of California Press. pp. 281-297.

[21] Bezdek, James C. (1981). Pattern Recognition with Fuzzy Objective Function Algorithms. ISBN 0-30640671-3

[22] R. Yager and D. Filev, "Generation of fuzzy rules by mountain clustering," J. of Intelligent and Fuzzy Systems, vol. 2, no. 3, pp. 209 - 219 (1994).

[23] S. Chiu, "Method and software for extracting fuzzy classification rules by subtractive clustering", Fuzzy Information Processing Society, NAFIPS, pp. 461 - 465 (1996). 